\title{
Stiffening material impact on the work of thin-walled element
}

\author{
Katarzyna Falkowicz, ${ }^{1 *}$ \\ ${ }^{1}$ Faculty of Mechanical Engineering, Department of Machine Design and Mechatronics, Nadbystrzycka 36, 20-618 Lublin, Poland
}

\begin{abstract}
The subject of research is a numerical analysis of a thin-walled plate with a cut-out and stiffening, made of laminate and subjected to axial compression. The plate was made of a carbon-epoxy composite - a laminate consisting of eight symmetrically oriented plies. The scope of the research included a linear and nonlinear numerical analysis using Finite Element Method (FEM). The main objective of the study was to investigate behaviour of the considered plate made of various stiffening materials, under quasi-static compression to achieve Tsai-Wu criterion. The numerical analysis was conducted with the Abaqus, commercial FEM software package.
\end{abstract}

\section{Introduction}

Thin-walled constructions [1] have many advantages, showing high load carrying capacity at a relatively low mass, giving the designer great freedom in shaping the constructional form. Such structures include hulls, aircraft wings or car bodies. However, due to low bending stiffness, they can carry a relatively small load. When they are compressed, a stability loss of bending-buckling character occurs at low load [2]. An example of such a loss is shown in Fig.1. The issue of stability is discussed in many works [3-7].

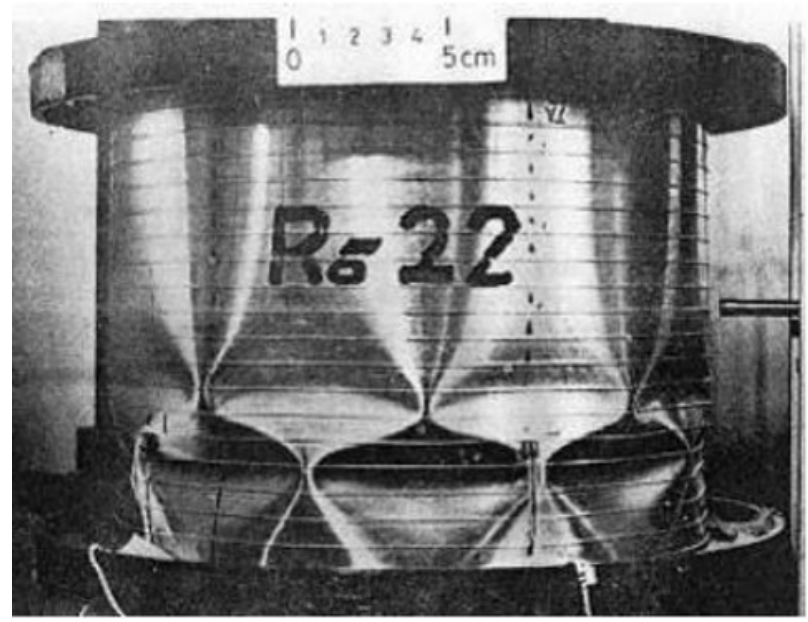

Fig. 1. Example of loss of stability [8].

However, it is possible to improve carrying capacity of the plate by making a notch in it and inducing deformations according to the higher, bending-twisting form of buckling, as it is described in this paper.

The analytical methods for determining deflexions and internal forces in plate elements were initiated by: Euler,
Bernoulli, Germain, Lagrange, Poisson, Navier (at the turn of the 18th and 19th century) [9]. The literature about theory of plates is abundant, and items [10-12] are especially worth-referring to. The issues of stability, postcritical behaviour and limit carrying capacity of plates with cut-outs, have been described, i.a., in the works: [13$15]$.

The subject for consideration in this paper are rectangular plates with a central cut-out, made of fibre composites with different layout of laminate layers and stiffening of different materials. The scope of the research included the linear and nonlinear issue of plate's composite structures stability subjected to uniform compression. Commercial ABAQUS program [16] was used to develop a discrete model and to perform calculation, using the finite element method [16], which currently has a very wide application [18-22]. In calculation the plate structure model was assumed. The value of critical load, depending on the material used for stiffening and the layout of composite layers, was determined. Performed numerical calculation was a solution to an eigenvalue problem of compressed structure, as well as non-linear analysis with the geometrically nonlinear issue. The non-linear analysis was carried out to achieve the Tsai-Wu criterion.

\section{Numerical Analysis}

The results of the research presented in [23] showed that the classic FEM approach to the analysis of post-critical behaviour, with the implemented higher buckling form, is inconsistent with real behaviour of the structure. However, due to the fact that the main assumptions remain in force, it was decided to search for a method to obtain the bending-twisting form as the lowest own form. The research was conducted towards disturbance of the asymmetry in the composite layer arrangement. The concept of sticking two strips of isotropic material

* Corresponding author: k.falkowicz@pollub.p1 
(aluminium) near the outer, vertical edges of the plate, one on each side, was applied [24]. The carried-out research has shown that the applied concept of plates with longitudinal reinforcements made of isotropic material placed asymmetrically relative to the plate plane, allows to obtain the lowest bending-twisting form of buckling (Fig. 2a), which was also supported by experimental tests (Fig. 2b). As mentioned before, the results were presented for a plate with pasted strips made of aluminium. This work focuses on the comparison of results for plates with stiffening made of various materials: steel, aluminium and composite. Numerical analysis was carried out for critical and post-critical states.

a)
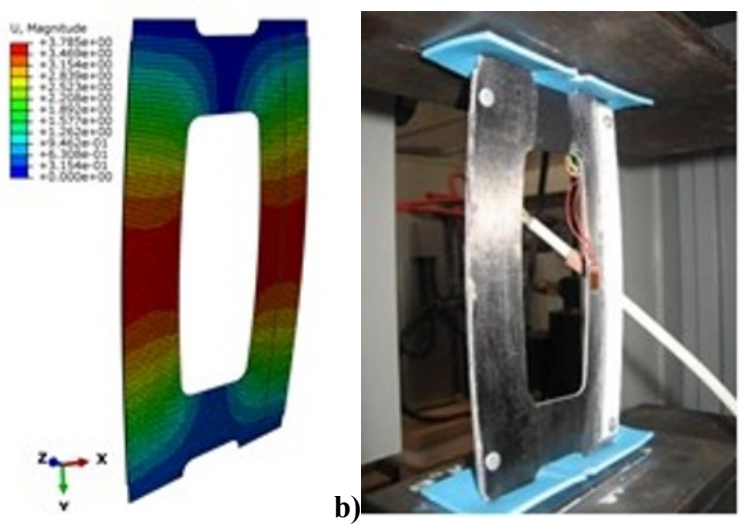

Fig. 2. Higher (stable) bending-twisting modes of the composite plates [0/-45/45/90]s: a) FEM, b) experiment.

\subsection{Study object}

The study was carried out on rectangular, composite plates with central cut-out. The height of plate was 160 [mm] and the width was $80[\mathrm{~mm}]$. The geometric parameters of cut-out were $30 \times 100$ [mm]. The plates were made of a unidirectional carbon/epoxy composite tape, arranged symmetrically to the central plane with the autoclave method. The experimentally determined mechanical properties of a single laminate layer were as follows (according to the relevant ISO standard): Young modulus in the fibre direction E1 $=130.71 \mathrm{GPa}$, Young modulus perpendicular to fibre direction $\mathrm{E} 2=6.36 \mathrm{GPa}$, Poisson's ratio in the layer plane $v 12=0.32$, Kirchhoff's modulus $\mathrm{G} 12=4.18 \mathrm{GPa}$. The real model of plate shown in Fig. 3.

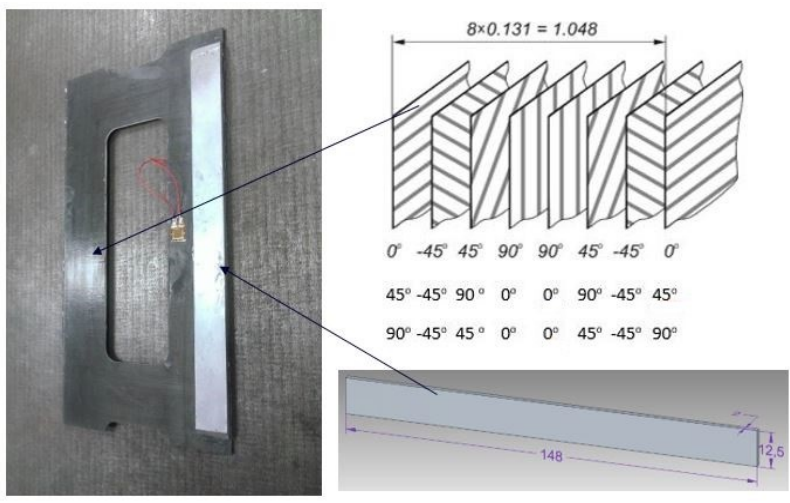

Fig. 3. Plate model with stiffening and with used the layers configurations.
The structure of laminate was composed of 8 layers with the same thickness equal 0.131 [mm], in symmetric arrangement of layers respectively to the centre plane of packet. The total thickness of plate was 1.048 [mm].

The research was carried out on composite plates with layers configurations: $[0 /-45 / 45 / 90] \mathrm{s},[45 /-45 / 90 / 0] \mathrm{s}$ and $[90 /-45 / 45 / 0]$ s.

\subsection{Numerical model}

The plate was supported, articulated, and loaded by compressive force, evenly distributed over the upper edge (Fig. 4). Discretisation of the plate was based on eightnode shell elements with reduced integration of the S8R type, having 6 degrees of freedom in each node. These are shell, thin-walled elements in which the deformations corresponding to the membrane state are determined on the basis of linear displacements, and the deformations of the bending state are described on the basis of angular displacements.

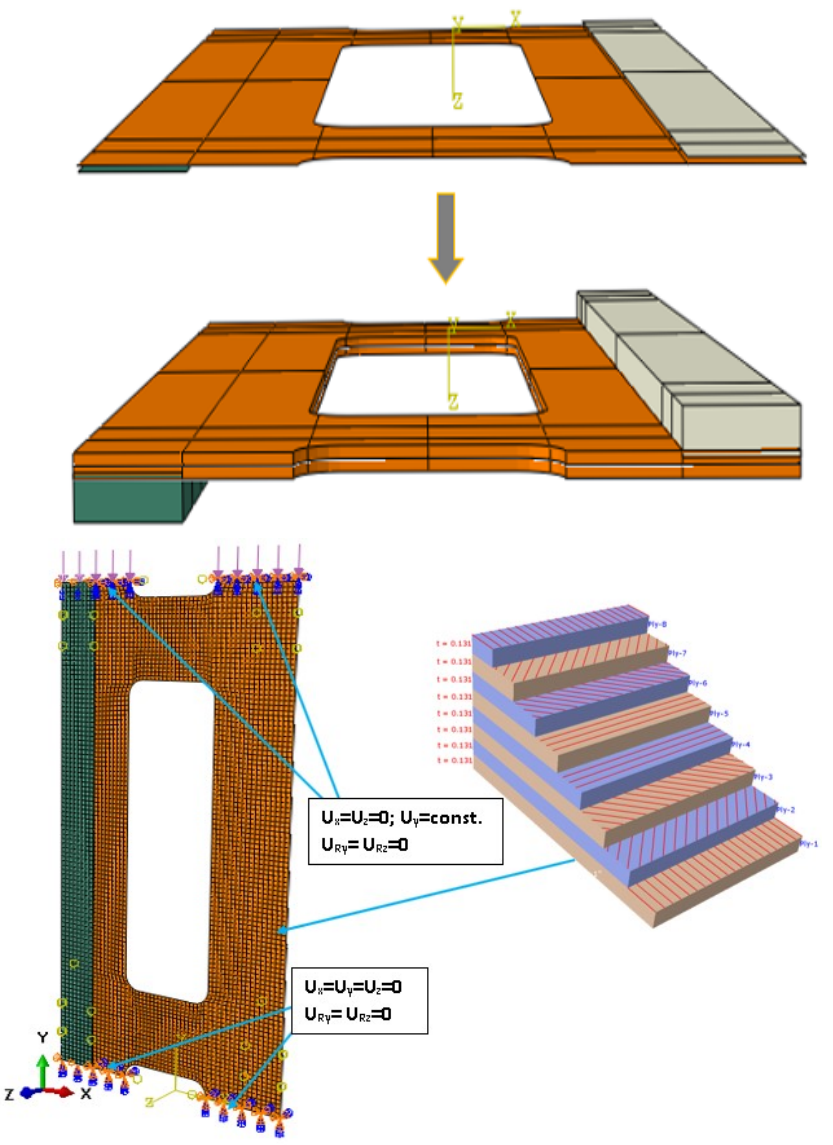

Fig. 4. FEM model of the tested composite plate with stiffening.

The structure of laminate was modelled by the LayupPly technique to reflect the layout of laminated layers over the thickness of the plate. Properties of the composite material were described by defining a model of orthotropic material in a two-dimensional state of stress. The boundary conditions of the model, depicting the articulated support of the plate, were defined by blocking the kinematic degrees of freedom of nodes located on the top and bottom edges of the plate. The articulated support of horizontal edges imposes conditions enabling rotation 
relative to the $\mathrm{x}$-axis. In addition, the upper edge, which is loaded, can move along the y-axis. Stiffening in the form of vertical strips have been conjoined with the plate by contacts.

\section{Results}

Aforementioned numerical calculation was carried out in two stages. The first stage was the analysis of the critical state of the structure with using a linear stability analysis - "buckling analysis", which allowed to determine the critical loads of the compressed plate element and buckling forms corresponding to it. The second stage of calculation, on the other hand, was a solution of nonlinear stability issue, in which calculation was carried out on a model with the initiated geometric imperfection corresponding to the bending-twisting form of structures buckling.

Carried-out numerical calculation was the basis for determining the critical force in analysed systems, depending on the used stiffeners material (Tab.1).

Table 1. The values of critical forces depending on the arrangement of layers and material of stiffeners.

\begin{tabular}{|c|c|c|c|}
\hline $\begin{array}{c}\text { Buckling load } \\
{[\mathrm{N}]}\end{array}$ & $\begin{array}{c}\text { Steel } \\
\text { stiffener }\end{array}$ & $\begin{array}{c}\text { Aluminium } \\
\text { stiffener }\end{array}$ & $\begin{array}{c}\text { Composite } \\
\text { stiffener }\end{array}$ \\
\hline$[0 /-45 / 45 / 90] \mathrm{s}$ & 2471.2 & 2432.3 & 2182 \\
\hline$[90 /-45 / 45 / 0] \mathrm{s}$ & 2692.9 & 2387.1 & 2206.8 \\
\hline$[45 /-45 / 90 / 0] \mathrm{s}$ & 2708.03 & 2571.2 & 2322.1 \\
\hline
\end{tabular}

For better illustration and comparison of critical forces, the results are summarised in a bar graph (Fig.5).

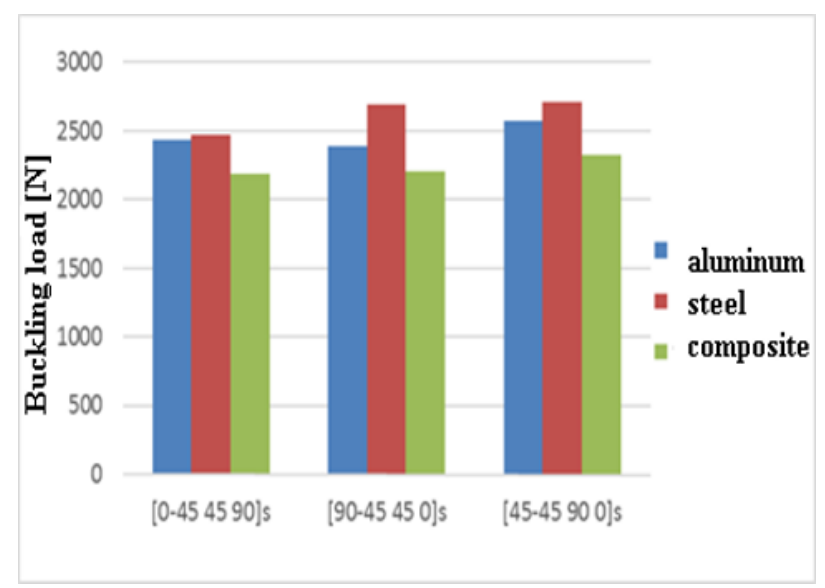

Fig. 5. Example results for plate with cut-out 30x100 for different types of fibre arrangement.

In Fig. 5 and Tab. 1, it can be seen that by changing the material of vertical stiffening strips, it is possible to influence on the value of critical force. The biggest noticeable differences are for the $[90 /-45 / 45 / 0] \mathrm{s}$ configuration. The best strength properties, in case of critical load, have shown plates with steel reinforcements. The obtained results of numerical calculation have also allowed to make a qualitative and quantitative assessment of the construction work in the post-critical state. The forms of post-critical plate deformation for all examined cases, have constituted a deepening of deformation of the implemented buckling form.

Exemplary characteristics showing the post-critical equilibrium paths for different stiffening materials, depending on the configuration of composite layers, are shown in Figs. 6-8., while, in Fig. 9, the post-critical equilibrium paths for one selected configuration of the composite layers are shown.

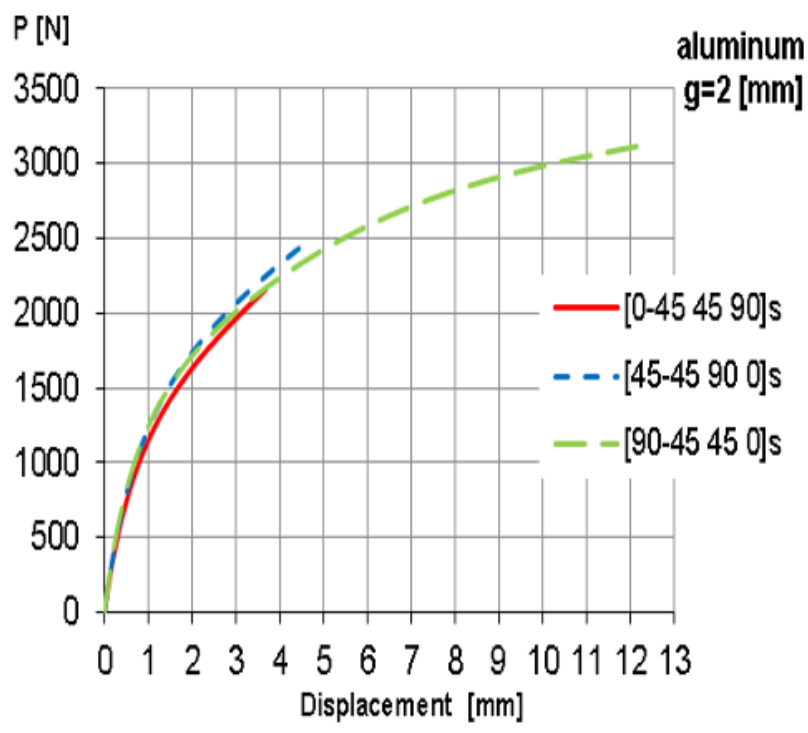

Fig. 6. Example results for plate with aluminium stiffening and with cut-out 30x100.

In the graph above, it can be noticed that with the aluminium stiffening, there is not much differences in stiffness of the plate.

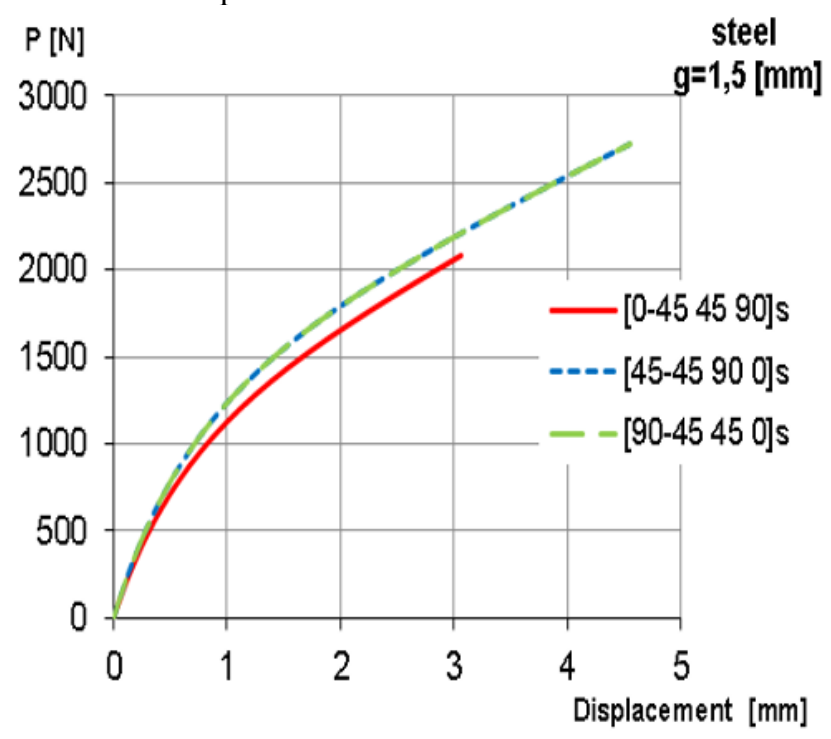

Fig. 7. Example results for plate with steel stiffening and with cut-out 30x100. 
In Fig. 7, where the paths for steel stiffening are compared, larger differences can be observed comparing aluminium stiffening (Fig. 6).

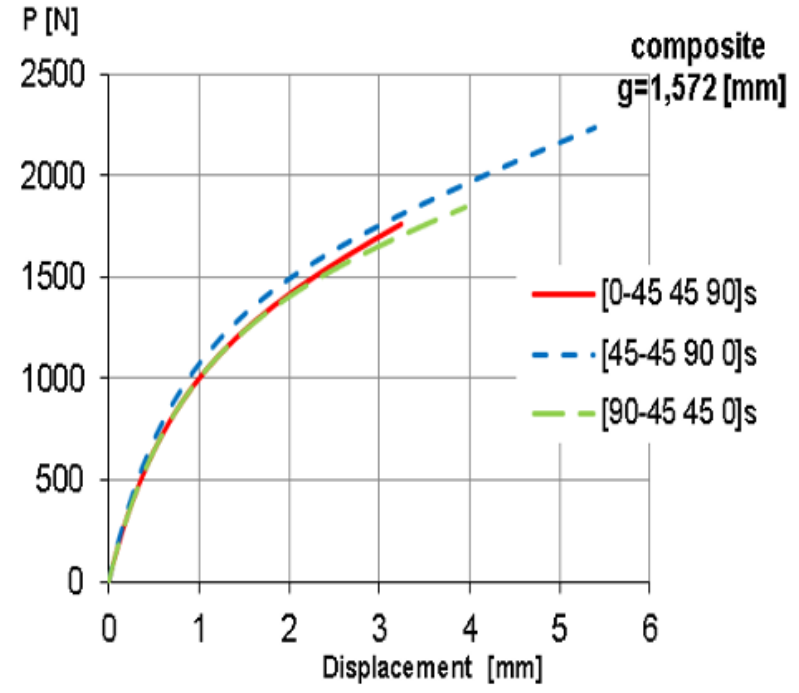

Fig. 8. Example results for plate with composite stiffening and with cut-out $30 \times 100$.

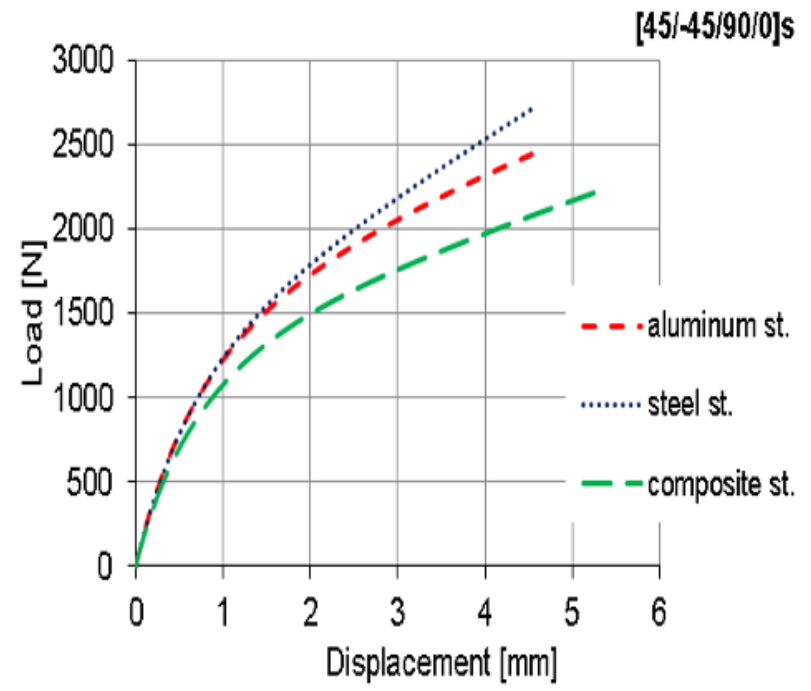

Fig. 9. Example results for plate with configuration $[45 /-45 / 90 / 0] \mathrm{s}$.

The quantitative analysis of the results has shown considerable differences in the load carrying capability for different materials of stiffening - in the case of a plate with stiffening made of composite - from $2240 \mathrm{~N}$ to 2720 $\mathrm{N}$ made of steel, for plate in $[45 /-45 / 90 / 0] \mathrm{s}$ configuration.

\section{Conclusions}

The presented results of the conducted research confirm that the basic objectives of the work were met, enabling the description of the stability issue of thin-walled composite plates with the cut-out, by computational methods. They allow for qualitative and quantitative assessment of construction work in both critical and postcritical areas.

The applied concept of plates with longitudinal reinforcements placed asymmetrically in relation to the plane of the plate allows to obtain the sought-for, the lowest form of buckling - bending-twisting form.

Based on obtained results, it can be seen that the best strength properties, in case of critical load, were shown by plates with steel reinforcements. Whereas, when it comes to the arrangement of composite layers, the smallest loads are transferred by the $[0 /-45 / 45 / 90]$ s configuration.

The above conclusions have important practical significance in the aspect of calculating a type of structures for application as elastic elements.

Results presented in the paper was obtained under the project UMO-2017/25/N/ST8/01066 financed by the National Science Centre Poland.

\section{References}

1. F.C. Cambell, Manufacturing Technology for Aerospace Structural Materials (Elsevier, 2006)

2. K. Falkowicz, ACE 63, 4, 161-172 (2017)

3. D. Banat, R.J. Mania, Thin Wall Struct. 122, 5263 (2017)

4. D. Banat, R.J. Mania, Compos Part B Eng. 112, 278-289 (2017)

5. P. Rozylo, H. Debski, P. Wysmulski, K. Falkowicz, Compos. Struct. 204, 207-216 (2018)

6. P. Wysmulski, Archives of Material Science and Engineering 85, 1 (2017)

7. P. Rozylo, H. Debski, J. Kral, AIP Conference Proceedings 1922, 080001 (2018)

8. http://www.mech.uwa.edu.au/DANotes/bucklin $\mathrm{g} /$ intro/intro.html

9. S.P. Timoshenko, The History of Material Strength (Arkady, Warsaw,1962)

10. S.P. Timoshenko, J.M.Gere, Theory of Elastic Stability (McGraw-Hill Book Company, NY, 1961)

11. J.S.N. Reddy, Mechanics of Laminated Composite Plates and Shells: Theory and Analysis (CRC Press, Boca Raton, 2004)

12. H. Altenbach, J. Altenbach, W. Kissing, Structural Analysis of Laminate and Sandwich Beams and Plates (Societatis Scientarium Lublinensis, Lublin, 2001)

13. R. Narayanan, F.Y. Chow, Thin Wall Struct, 2,2, 241-264 (1984)

14. D. Ouinas, B. Achour, Comp. Part B 55, 575-579 (2013)

15. K. Dinesh, S.B. Singh, Compos. Struct. 92, 769779 (2010).

16. Abaqus HTML Documentation

17. Rusinski E., Czmochowski J., Smolnicki T. Advanced Finite Element Method in stability construction (Wroclaw University of Technology Press (in Polish), 2000)

18. J. Gajewski, P. Golewski, and T. Sadowski, Compos. Struct. 159, 589-599 (2017) 
19. J. Gajewski and T. Sadowski, Comput. Mater. Sci. 82, 114-117 (2014)

20. R. Karpinski, L. Jaworski, M. Szala, M. Manko, ITM Web of Conferences 15, 07006 (2017)

21. R. Karpinski, L. Jaworski, J. Zubrzycki, Adv. Sci. Technol. Res. J. 10, 31, 240-246 (2016)
22. N. Kepczak, W. Pawlowski, L. Kaczmarek, Arch Metall Mater. 60, 2 (2015)

23. K. Falkowicz, H. Debski H., Adv. Sci. Technol. Res. J. 11, 186-193 (2017)

24. K. Falkowicz, H. Debski, A. Teter, AIP Conference Proceedings 1922, 080004 (2018) 